\title{
Multibranched Frozen Elephant Trunk with Left Subclavian Artery Cannulation
}

\author{
Gian Luca Martinelli, MD*, Alessandro Vivacqua, MD, Maurizio Braccio, MD, \\ Attilio Cotroneo, MD, Pierpaolo Greco, Mauro Cassese, MD \\ Department of Cardiovascular Surgery, Clinica Santa Maria, Bari, Italy
}

\begin{abstract}
Patients with aortic pathology involving the ascending aorta, the arch, and the descending aorta present a complex surgical challenge. A one-step hybrid procedure with ascending aorta repair, arch debranching, and frozen elephant trunk is reported in five patients. Left subclavian artery side graft cannulation is used to perfuse the spinal cord during circulatory arrest time.

Copyright $\odot 2014$ Science International Corp.
\end{abstract}

\section{Key Words}

Aorta - Aortic dissection - Cerebral protection - Spinal cord · Endovascular - Dissection

\section{Introduction}

The treatment of complex aortic pathology involving the ascending aorta, the arch, and the descending aorta at the same time represents a surgical challenge, with high postoperative morbidity and mortality. We describe a hybrid one-step procedure that simplifies the distal anastomosis and may reduce the risk of paraplegia through a continuous perfusion of the left subclavian artery (LSA) during the circulatory arrest time.

\section{Technique}

Standard general anesthesia is performed. An 8-french introducer is percutaneously inserted into the femoral artery, and a floppy wire is inserted into

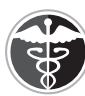

Fax +1 2037853346

E-Mail: aorta@scienceinternational.org

http://aorta.scienceinternational.org

\section{(c) 2014 Aorta.}

Published by Science International Corp. ISSN 2325-4637

\section{Accessible online at:}

http://aorta.scienceinternational.org the ascending aorta followed by a pigtail catheter. The left subclavian artery is prepared for cannulation. A median sternotomy is performed and isolation of the epiaortic vessels is achieved before giving heparin. After extracorporeal circulation (ECC) between a side graft sewed on the left subclavian artery and the right atrium, the patient is cooled down to a temperature of $24^{\circ} \mathrm{C}$. The ascending aorta is clamped, the aorta is opened, and the cardioplegia is given. The proximal anastomosis is performed and the sinus of Valsalva and the aortic valve are addressed if needed. When the patient has been cooled down, the circulation is arrested. The innominate artery and the left common carotid artery are divided and cerebral perfusion is obtained through selective anterograde perfusion of those vessels. The flow is maintained at 10 $\mathrm{mL} / \mathrm{kg} / \mathrm{min}$, keeping a perfusion pressure between 50 and $60 \mathrm{~mm} \mathrm{Hg}$. The pressure is monitored from the right radial artery and from the left carotid artery. The trend of the cerebral oxygen-saturation is monitored. The left subclavian artery is then ligated proximally and the vertebral artery and the spine branches are perfused during the circulatory arrest time.

The distal aorta is prepared for anastomosis. A stiff wire is inserted from the tip of the pigtail and advanced outside of the femoral introducer. The catheter is removed and the stent delivery system is moved along the wire. A $15 \mathrm{~cm}$ stent graft is then deployed in an anterograde fashion just before the innominate artery (zone 1). The size of the graft is chosen to match the diameter of the distal landing zone. The

\footnotetext{
*Corresponding author:

Gian Luca Martinelli, MD

Via Oslavia 50

Rome 00195, Italy

Tel: +3906 372 0034, Fax: +3906976 56623, E-Mail: martinelligluca@gmail.com
} 


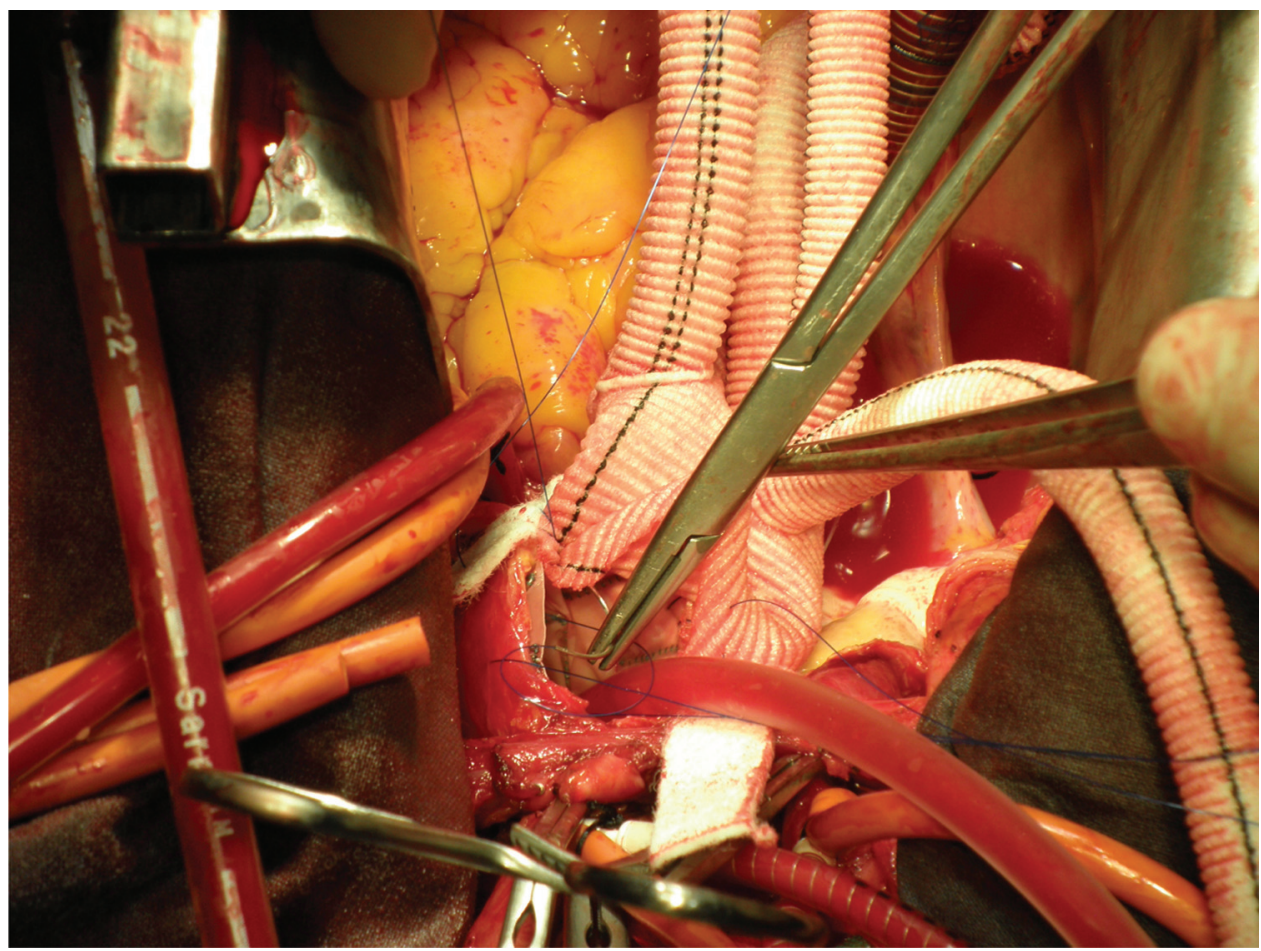

Figure 1. Distal suture line at zone 1 including the stent graft.

distal anastomosis is then performed including the stent in the suture to guarantee proximal sealing (Fig. 1). Lower body circulation is restarted through cannulation of a side branch of the prosthesis and the heart is perfused. The epiaortic vessels are anastomosed individually in an end-to-end fashion using the branches of the prosthesis (Fig. 2). At the end of the operation, off pump, the prosthetic side graft is led to the ascending aorta with the help of a Bengolea forceps (Sklar Surgical, Westchester, PA) through the second intercostal space. Then it is anastomosed directly to the multibranched graft. In order to avoid kinking, we suggest using the anterior branch, which allows a harmonious take-off from the ascending aorta and follows the normal anatomy of the left subclavian artery.

Five patients underwent this procedure. Three patients had an acute aortic dissection with an intimal tear starting below the left subclavian in two cases and in the distal arch in one case. One patient had a chronic dissection, previously treated with an ascending aorta repair, with a pseudoaneurysm of the ascending aorta at the level of the distal anastomosis and a rapidly enlarging false lumen in the descending aorta. One patient had a degenerative aneurysm of the ascending arch and of the descending aorta. There was one death in the acute dissection group due to early postoperative rupture of the right coronary sinus in a patient treated with a supracoronary graft. The other four patients had no neurological complications, nor prolonged respiratory problems, but one patient required temporary dialysis.

\section{Comment}

The use of the frozen elephant trunk (FET) to treat complex pathologies of the aorta was introduced by Kato [1] in the mid-1990s. Since then, many hybrid solutions have been reported to reduce mortality and morbidity and achieve an extensive treatment of the aorta $[2,3]$.

The technique described here allows performance of the distal anastomosis more proximally, promoting a better view and better control of the suturing with potentially less leakage. This reduces the time of the circulatory arrest. In all cases the lower body circulatory arrest time was less than 35 minutes. During this time we continuously perfused the three epiaortic vessels. Other advantages are avoidance of bleeding from the distal arch and avoidance of recurrent laryngeal nerve injury. The proximal fixation of the stent 


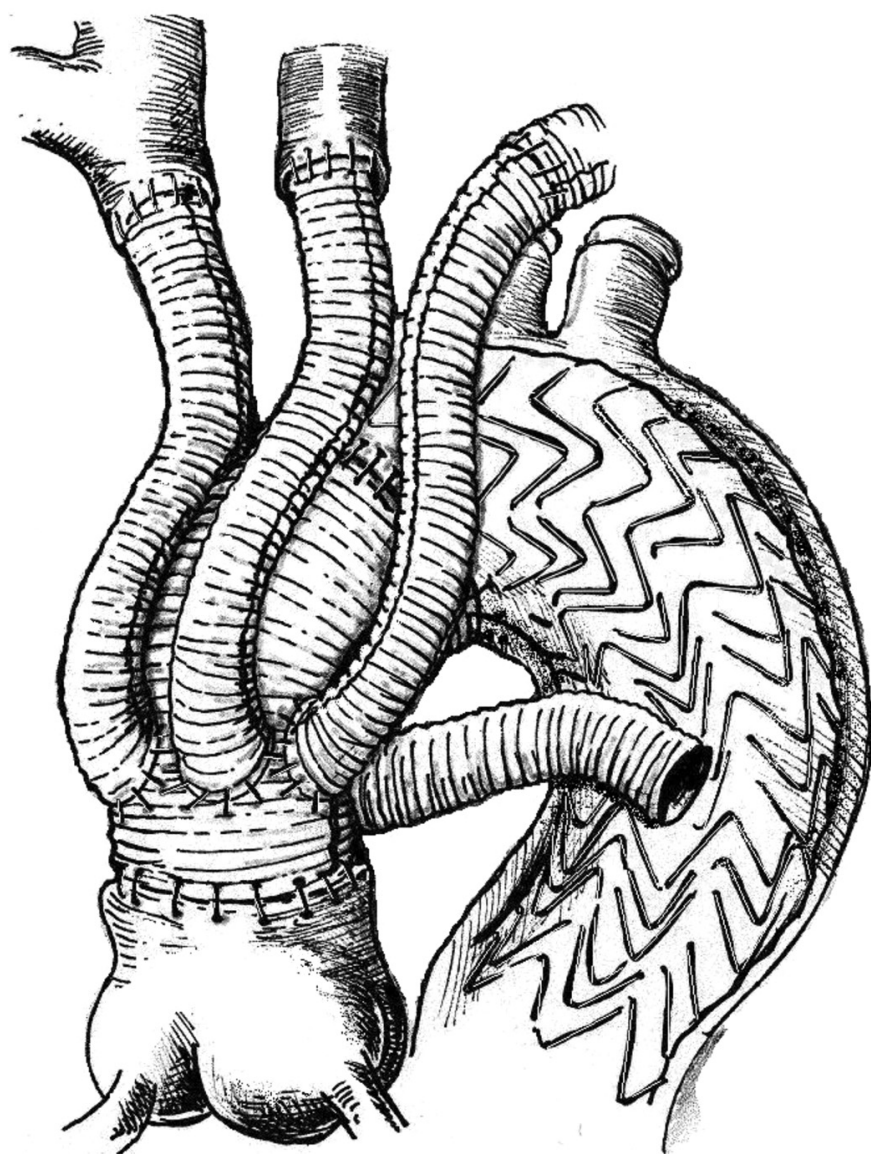

Figure 2. Final result with the stent graft deployed and the epiaortic vessels reimplanted.

graft prevents Type 1A endoleak and any possible further migration in the future. An important step in the planning of the procedure is choosing the diameter of the stent graft that matches the distal landing zone in the descending aorta. We measure the aorta at the level of the bifurcation of the pulmonary artery. In acute dissection, we never oversize the graft by more than $10 \%$.

Ischemic spinal cord injury represents a concern of the FET technique. Flores et al. [4] reported a $24 \%$ incidence of paraplegia, and identified a distal landing zone of $\mathrm{T7}$ or lower and a history of abdominal aortic aneurysm repair as the strongest predictors of spinal cord injury $(\mathrm{SCl})$. In other series, $\mathrm{SCl}$ occurred from 3 to $9 \%$ of the cases [5-7].

The use of the left subclavian side graft cannulation offers the advantage of continuous perfusion of all cervical spinal branches during circulatory arrest and might reduce the risk of paraplegia. Moreover, it a

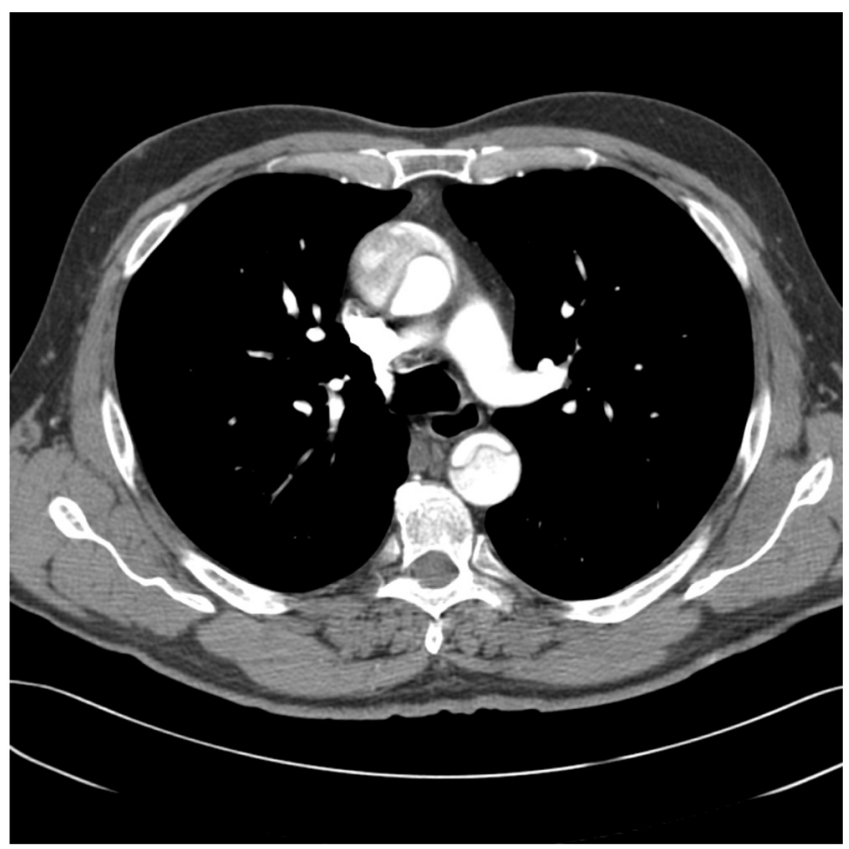

b

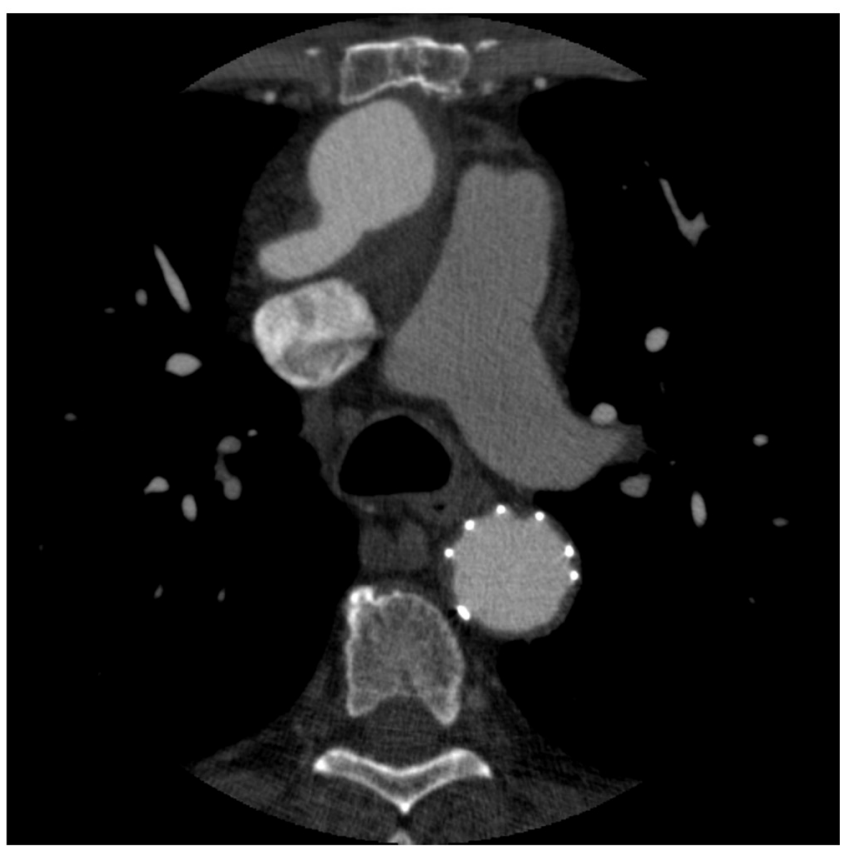

Figure 3. (a) Preoperative CT scan of a patient with aortic dissection. (b) Postoperative CT scan showing complete shrinkage of the false lumen.

facilitates the subclavian reimplantation by tunneling the side graft into the chest through the second intercostal space.

In patients with Type A aortic dissection, we adopted this technique when the tear was in the distal arch or in the proximal descending aorta. The great 
advantage is to facilitate the distal anastomosis and at the same time exclude the entry tear promoting thrombo-exclusion of the false lumen and preventing enlargement of the aorta in that segment. At the level of the stent graft we observed a complete shrinkage of the false lumen (Fig. 3). However, false lumen patency downstream from the FET prosthesis is still a concern due to the presence of low thoracic and abdominal aortic re-entry [8].

As for all aortic pathologies, careful imaging is the key to success. Identifying the entry tear, locating re-entries at lower levels, measuring the arch, the descending aorta, and the false lumen are essential in planning the surgery correctly. In the case of chronic aortic dissection, the absence of distal re-entry associated with the take-off of the visceral arteries from the false lumen is a contraindication to this procedure.
We should be sure that all visceral vessels are well perfused at the end of the operation. Only in a hybrid operating room is it possible to check normal perfusion with an angiogram.

In conclusion, in patients who require arch and proximal descending aorta treatment under circulatory arrest, the use of a multibranched frozen elephant trunk with left subclavian side graft cannulation facilitates the operation and may reduce the risk of paraplegia and cerebrovascular accident.

\section{Conflict of Interest}

The authors have no conflict of interest relevant to this publication.

\section{Comment on this Article or Ask a Question}

\section{References}

1. Kato M, Ohnishi K, Kaneko M, Ueda T, Kishi D, Mizushima T, et al. New graft-implanting method for thoracic aortic aneurysm or dissection with a stented graft. Circulation. 1996; 94(9 Suppl):II188-II193.

2. Criado FJ, Clark NS, Barnatan MF. Stent graft repair in the aortic arch and descending thoracic aorta: a 4-year experience. J Vasc Surg. 2002;36:1121-1128. 10.1067/mva.2002. 129649

3. Karck M, Chavan A, Hagl C, Friedrich H, Galanski $M$, Haverich $A$. The frozen elephant trunk technique: a new treatment for thoracic aortic aneurysms. J Thorac Cardiovasc Surg. 2003;125: 1550-1553. 10.1016/S0022-5223(03)00045-X

4. Flores J, Kunihara T, Shiiya N, Yoshimoto K, Matsuzaki K, Yasuda K. Extensive deployment of the stented elephant trunk is associated with an increased risk of spinal cord injury. J
Thorac Cardiovasc Surg. 2006;131:336-342. 10. 1016/j.jtcvs.2005.09.050

5. Shimamura K, Kuratani T, Matsumiya G, Shirakawa $\mathrm{Y}$, Takeuchi $\mathrm{M}$, Takano $\mathrm{H}$, et al. Hybrid endovascular aortic arch repair using branched endoprosthesis: the second-generation "branched" open stent-grafting technique. J Thorac Cardiovasc Surg. 2009;138:46-52; discussion 52-53. 10.1016/j.jtcvs.2009.03.025

6. Di Bartolomeo R, Di Marco L, Armaro A, Marsilli $D$, Leone $A$, Pilato $E$, et al. Treatment of complex disease of the thoracic aorta: the frozen elephant trunk technique with the Evita open prosthesis. Eur J Cardiothorac Surg. 2009;35:671-675; discussion 675-676.10.1016/ j.ejcts.2008.12.010

7. Pochettino A, Brinkman WT, Moeller P, Szeto WY, Moser W, Cornelius K, et al. Antegrade thoracic stent grafting during repair of acute DeBakey I dissection prevents development of thoracoabdominal aortic aneurysms. Ann
Thorac Surg. 2009;88:482-489; discussion 489-490. 10.1016/j.athoracsur.2009.04.046

8. Uchida N, Shibamura H, Katayama A, Shimada $N$, Sutoh M, Ishihara H. Operative strategy for acute type $A$ aortic dissection: ascending aortic or hemiarch versus total arch replacement with frozen elephant trunk. Ann Thorac Surg. 2009;87:773-777. 10.1016/j.athoracsur.2008. 11.061

Cite this article as: Martinelli $G \mathrm{~L}$ Vivacqua $A$, Braccio $M$, Cotroneo $A$, Greco P, Cassese M, Multibranched Frozen Elephant Trunk with Left Subclavian Artery Cannulation. Aorta 2014;2(2):87-90.

DOI: j.aorta.2014.13-057 